\title{
Suggesting alternatives for reinforced concrete deep beams by reinforcing struts and ties
}

\author{
Khattab Saleem Abdul-Razzaq ${ }^{1 *}$, and Sarah Farhan Jebur ${ }^{2}$ \\ ${ }^{1}$ Department of Civil Engineering, Diyala University, Iraq. \\ ${ }^{2}$ Department of Civil Engineering, Diyala University, Iraq.
}

\begin{abstract}
This paper studied reinforcing struts and ties in deep beams based on the Strut-and-Tie Model (STM) of ACI 318M-14. The study contained testing 9 simply supported specimens, divided into 3 groups. The difference between the groups was the loading type which was 2concentrated forces, 1-concentrated force and uniformly distributed load. Each group contained three specimens; the first specimens in each group were conventional deep beams as references which had a length of 1400 $\mathrm{mm}$, a height of $400 \mathrm{~mm}$ and a width of $150 \mathrm{~mm}$. The second specimens were the same as references in dimensions, but with removing shoulders. In addition, only the paths of struts \& ties of STM were reinforced in the second specimens as compression and tension members, respectively. The third specimens were the frames that took their dimensions from STM of ACI $318 \mathrm{M}-14$. From the experimental work, it is found that the proposed frames were good alternatives for the references despite the small loss in ultimate capacity. However, these proposed frames already carried loads greater than the factored design loads of STM. In comparison with the references, these proposed frames provided $41-51 \%$ reduction in weight, $4-27 \%$ reduction in cost besides providing front side area about $46-55 \%$.
\end{abstract}

\section{Introduction}

The reinforced concrete deep beam is a very important structural element in various types of concrete structures. It is generally distinguished as short and deep, having a small thickness in comparison with their span or depth. Typical applications of deep beam comprise foundation pile caps, transfer girders, tanks, folded plates of roof structures, shear walls, offshore structures and foundation walls. It is commonly received many small loads in their own plane and transferring them to a small number of reaction points through compressive struts that connected by ties [1]. The strut and tie models are particularly appropriate for designing the discontinuity in the stress distribution regions where the distribution of strain is nonlinear within the deep beam cross section [2]. Modeling the deep beam as strut-and-tie has been confirmed a safe method, unified and rational for designing

\footnotetext{
* Corresponding author: dr.khattabsaleem@yahoo.com
} 
the reinforced concrete members under variable loadings [3] despite the fact that it is conservative in some cases [4].

The problem of filling areas between crowded reinforcement is critical because the deep beam heavy reinforcement. In addition, the deep beam has a heavy weight, a big volume and its wide front side intercepts the cables, pipes or ducts from passing through. The present study was then an attempt to reinforce struts and ties paths in order to find alternatives for the conventional $\mathrm{RC}$ deep beams. The aim was to reduce cost and weight in addition to gain a front side area that can be used for service utilities.

\section{Experimental program}

The experimental program consisted of constructing and testing nine simply supported SCC specimens, divided into three groups (A, B and C) as shown in Figure 1. Each group consisted of three specimens. The first specimens in each group were conventional deep beams (DB.2P, DB.1P and DB.U specimens). The second specimens in each group were deep beams in which only the paths defined by STM of ACI 318M-14[5] were reinforced (STM.2P, STM.1P and STM.U specimens) besides removing the shoulders of the specimens STM.1P and STM.U. Finally, the third specimens in each group were the reinforced concrete frames (FR.2P, FR.1P and FR.U specimens) that took their dimensions from the load paths defined by STM, then reinforced according to ACI 318M-14.

It is worth to mention that the struts in the specimen STM.2P, STM.1P, STM.U, FR.2P, FR.1P and FR.U were reinforced as compression members using the (Interaction Diagram of Rectangular Columns) while the ties were reinforced as tension members (22.4.3.1) of ACI $318 \mathrm{M}-14$. It is also worth to mention that the section of every frame was unified; the width was $b=150 \mathrm{~mm}$ (the width of the reference beams) and height was $\mathrm{w}_{\mathrm{sb}}$ (STM section height at the bottom of the inclined struts). In order to recognize specimens designation easily, Table 1 shows the way followed in this designation.

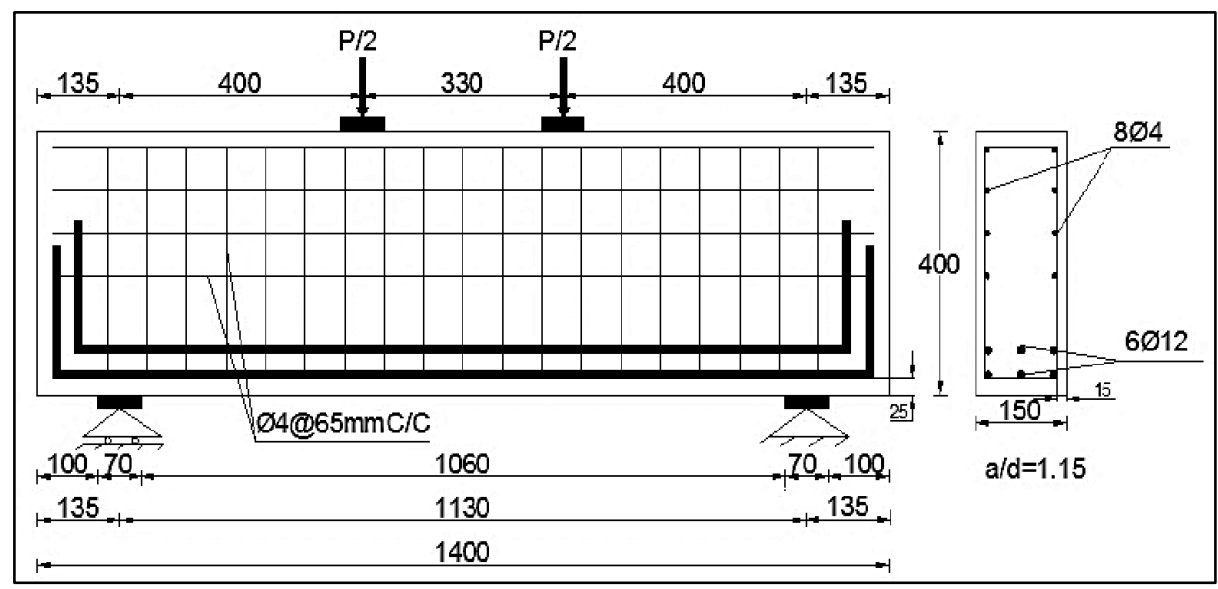

Group A : DB.2P 


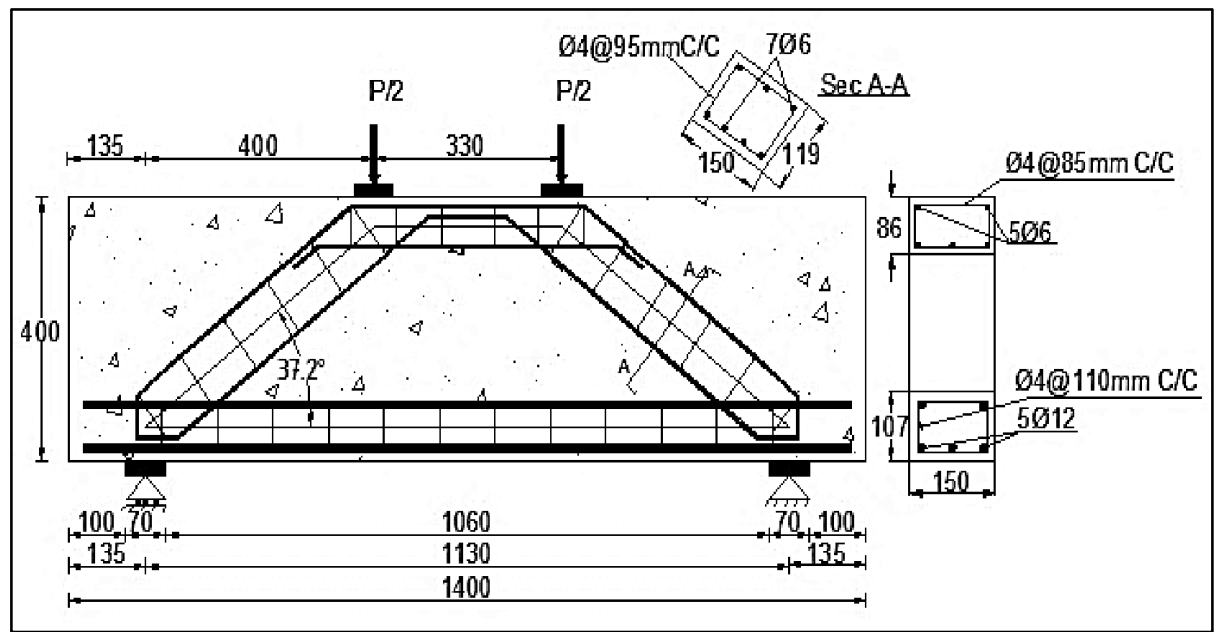

\section{Group A : STM.2P}

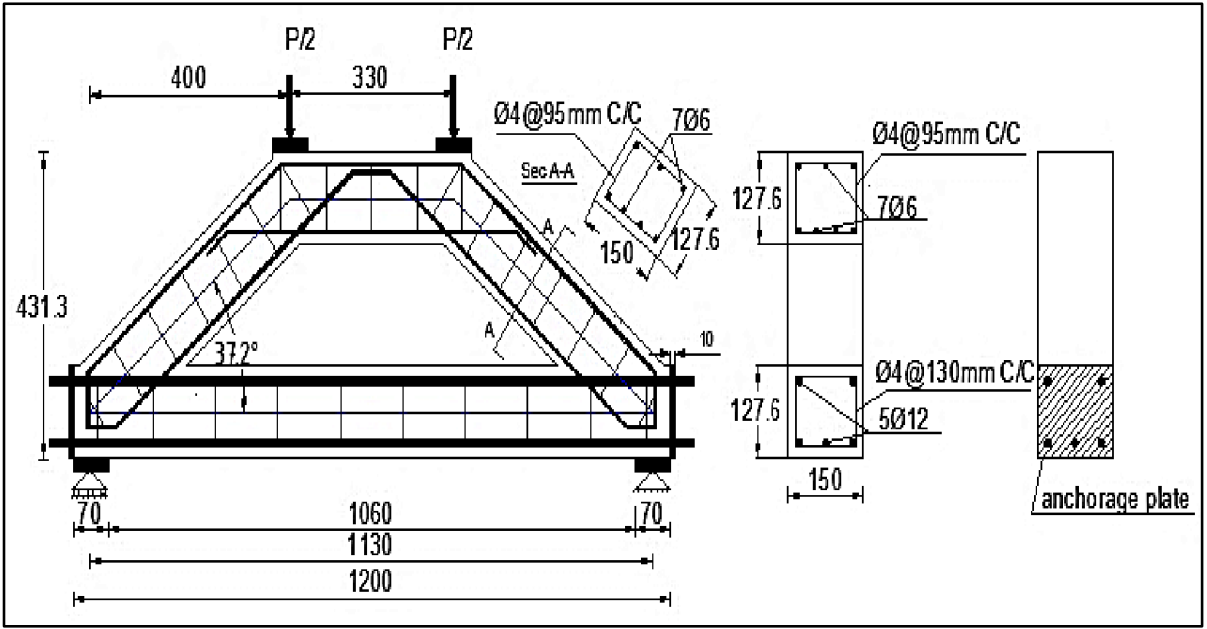

\footnotetext{
Group A : FR.2P
}

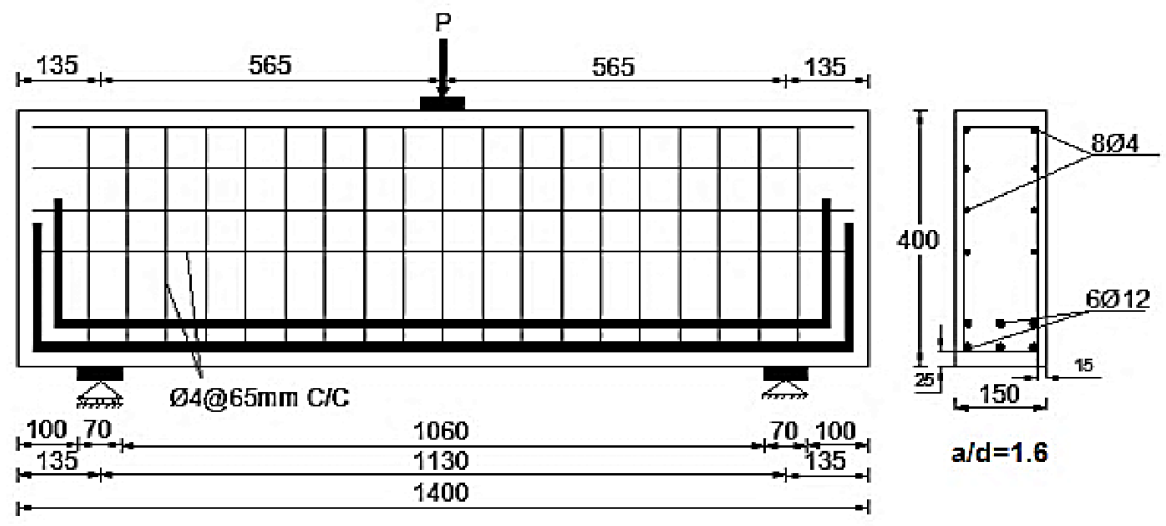

Group B : DB.1P 


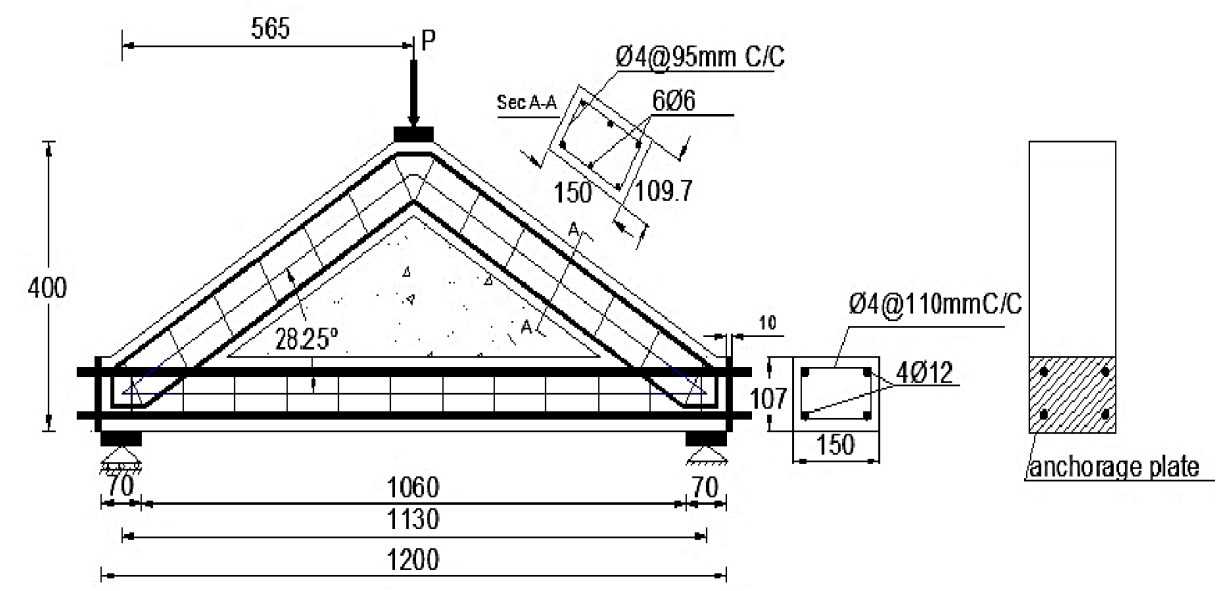

Group B :STM.1P

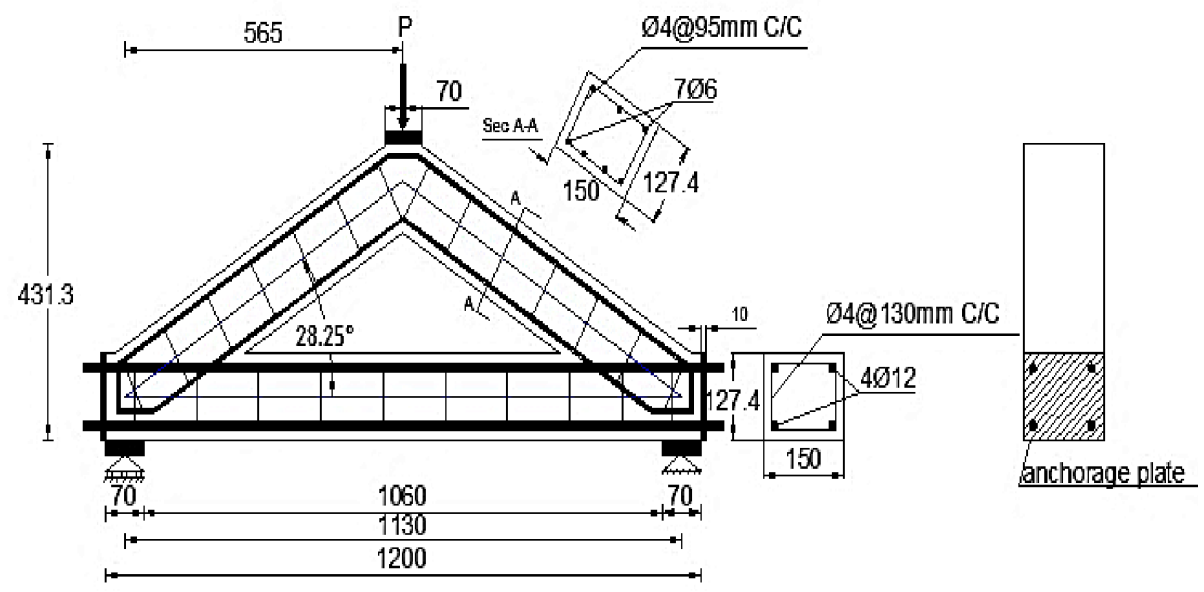

Group B : FR.1P

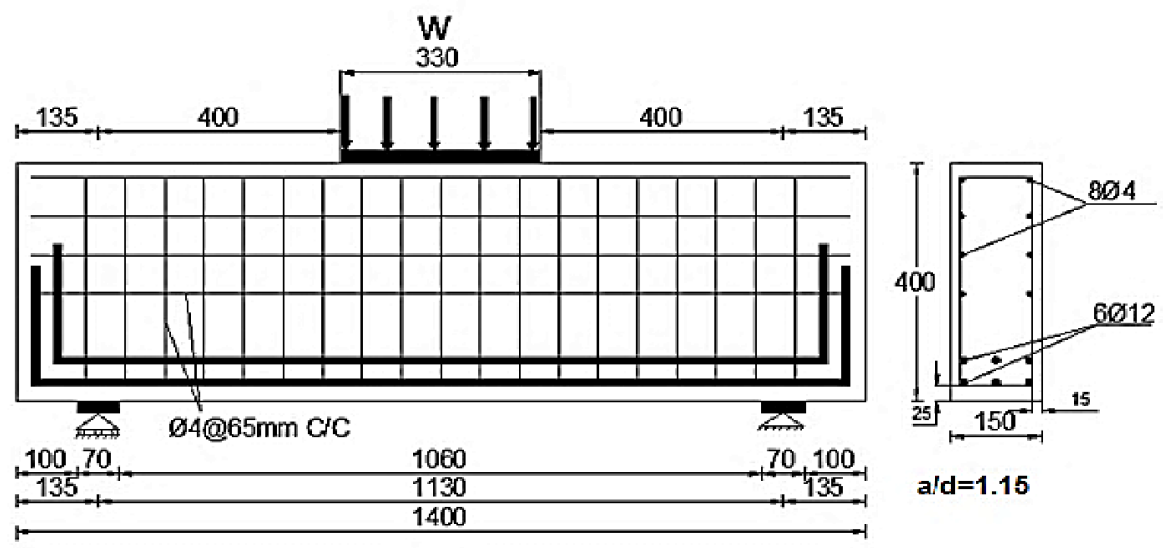

Group C : DB.U 


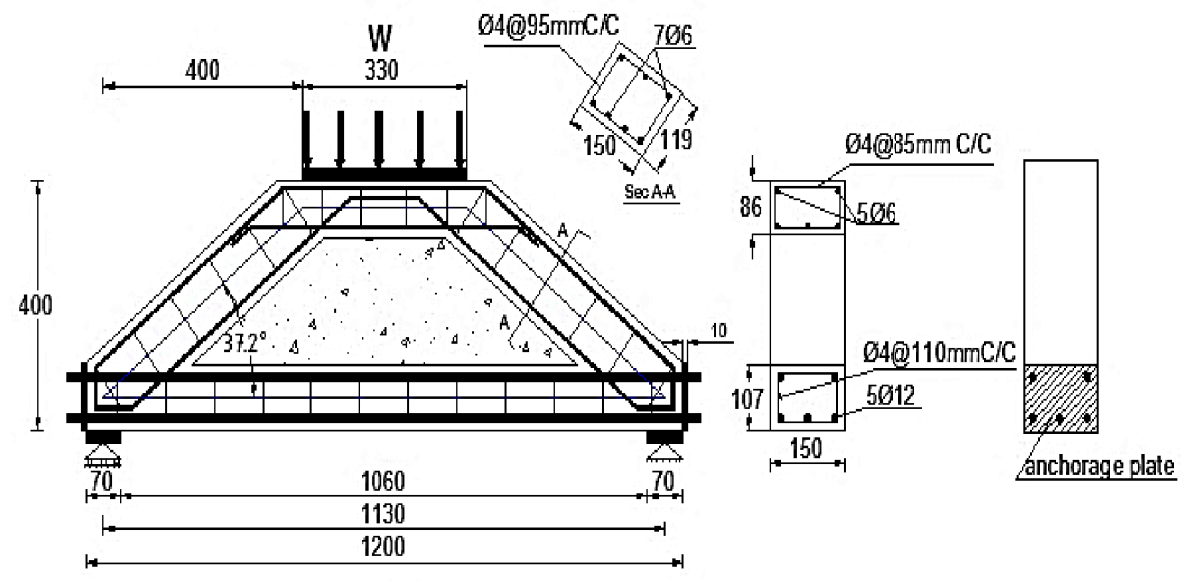

\section{Group C : STM.U}

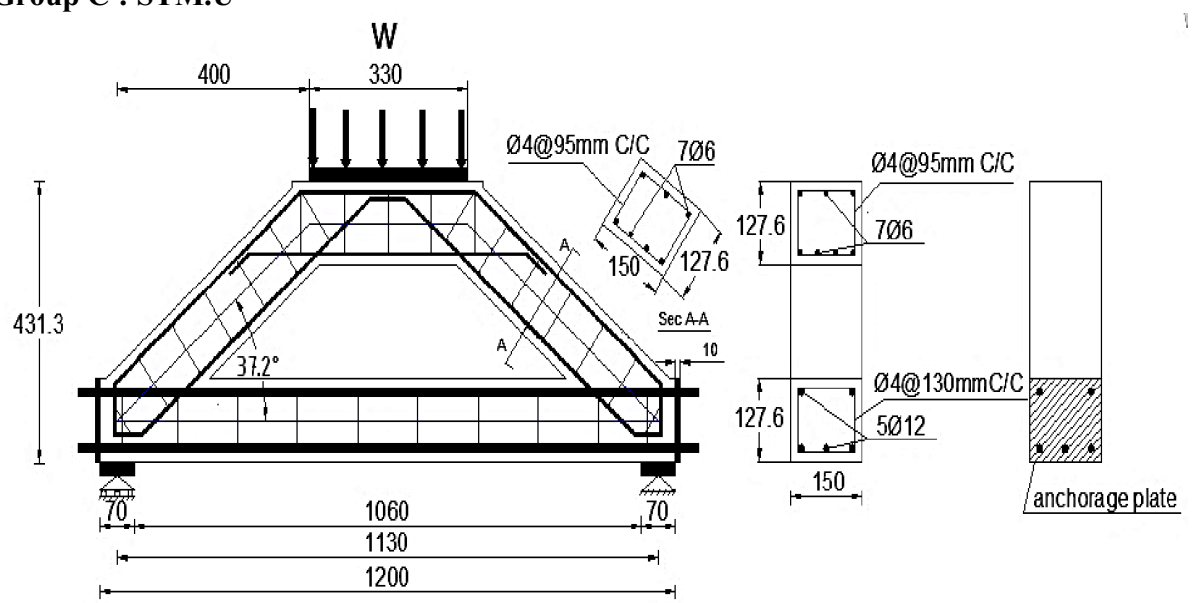

Group C : FR.U

Fig. 1. The Nine Specimens, all dimensions are in $\mathrm{mm}$.

Table 1. Specimens designation way.

\begin{tabular}{|c|c|}
\hline Letter & Meaning \\
\hline DB & Conventional $\underline{\text { Deep }} \underline{\mathbf{B} e a m}$ \\
\hline STM & Only paths drawn by $\underline{\text { STM }}$ were reinforced in deep beam \\
\hline FR & Reinforced Concrete $\underline{\text { FRame that took its geometry from STM stress paths }}$ \\
\hline 1P & Subjected to $\underline{\mathbf{1}}$-concentrated force $(\underline{\mathbf{P}})$ \\
\hline 2P & Subjected to $\underline{\mathbf{2}}$-concentrated forces $(\underline{\mathbf{2 P}})$, which means actually $(2 * 0.5 \mathrm{P})$ \\
\hline U & Subjected to $\underline{\text { Uniformly Distributed load }}$ \\
\hline
\end{tabular}

\subsection{Material properties}

The properties of the materials such as cement, aggregates, additives and reinforcing steel used for preparing the reinforced self-compacted concrete (SCC) specimens tested in this study were as follows: 
Ordinary Portland cement type I of Tasluja factory was used for producing SCC. Local AlUkhaider graded natural sand with 2.63 fineness modulus. The coarse aggregate $(10 \mathrm{~mm}$ maximum particles size of crushed gravel) was used in SCC mixtures. According to EFNARC [6], the limestone powder particle size was less than $0.125 \mathrm{~mm}$. Turbid liquid Sika ViscoCrete 5930 was used in SCC mixtures which submitted with ASTM C 494/C 494M-99a [7] types $\mathrm{G}$ and $\mathrm{F}$ (free from chlorides). Deformed steel bars of diameter $12 \& 6$ $\mathrm{mm} \quad\left(f_{y}=550 \mathrm{MPa}\right.$ and $f_{y}=572 \mathrm{MPa}$, respectively) were used as longitudinal reinforcement for the specimens. Deformed steel bars of diameter $4 \mathrm{~mm}\left(f_{y}=604 \mathrm{MPa}\right)$ were used for the vertical and horizontal shear reinforcement of the specimens.

During constructing every group, six standard $150 \mathrm{~mm} \times 300 \mathrm{~mm}$ cylinders were cast. Three cylinders were used to measure the compressive strength $\left(f^{\prime}{ }_{c}\right)$ and the remaining three for split tensile strength $\left(f_{c t}\right)$. In addition to that, three $500 \mathrm{~mm} \times 100 \mathrm{~mm} \times 100 \mathrm{~mm}$ prisms were cast and used for testing the concrete modulus of rapture $\left(f_{r}\right)$. All specimens were demolded about 24 hours after casting, and then cured by using dump blanket (cover) and sprinkled continuously with water for 28 days. Then, the specimens were white painted to help in the observation of crack propagations during testing. The mixed concrete properties are summarized in Table 2.

Table 2. Mix proportions of SCC.

\begin{tabular}{|c|c|c|c|c|}
\hline Group & $\boldsymbol{f}^{\prime}{ }_{\boldsymbol{c}}$ (MPa) & $\boldsymbol{f}_{\boldsymbol{c t}}$ (MPa) & $\begin{array}{c}\boldsymbol{f}_{\boldsymbol{r}} \\
(\mathbf{M P a})\end{array}$ & $\left.\mathbf{E}_{\boldsymbol{c}}{ }^{*} \mathbf{M P a}\right)$ \\
\hline $\mathrm{A}$ & 35 & 3.838 & 6 & 27805 \\
\hline $\mathrm{B}$ & 34.4 & 3.824 & 5.75 & 27566 \\
\hline $\mathrm{C}$ & 34.1 & 3.812 & 5.7 & 27445 \\
\hline
\end{tabular}

*The values of $\mathrm{E}_{\mathrm{c}}$ were calculated by $\left(4700 \sqrt{f_{c}^{\prime}}\right)$ provided by (ACI $\left.318 \mathrm{M}-2014\right)$

\subsection{Test set-up and instrumentation}

The specimens were tested using a hydraulically universal testing machine of $2000 \mathrm{kN}$ capacity (Jet materials Ltd. Company). The tests were conducted under monotonic static loading up to failure at the Structural Laboratory / College of Engineering / University of Diyala. The tested specimens were simply supported at the ends and loaded with three different types of loadings; 2-concentrated forces, 1-concentrated force and uniformly distributed load. One dial gauge of $0.01 \mathrm{~mm}$ accuracy was fixed under the specimen to calculate the deflection at mid-span. A micro-crack meter device with an accuracy of 0.02 $\mathrm{mm}$ was used to detect and measure first crack width development at all loading stages for all specimens.

\section{Experimental results and discussions}

\subsection{General behavior of the specimens}

Nine SCC specimens were subjected to increasing static monotonic loads until failure as shown in Plates 1 to 9. Table 3 summarizes the test results for all specimens. 
Table 3. Summary of test results for tested specimens.

\begin{tabular}{|c|c|c|c|c|c|c|c|c|c|c|c|c|c|c|c|}
\hline 官 & 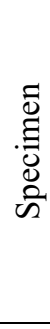 & 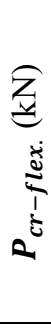 & 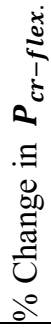 & 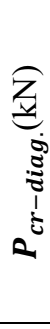 & 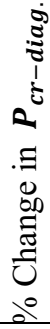 & 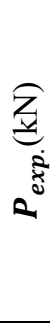 & 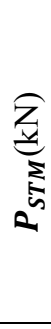 & $\frac{2^{5}}{2^{5}}$ & 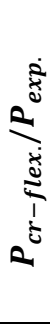 & 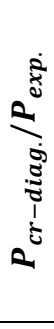 & 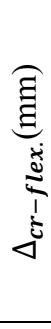 & 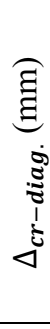 & 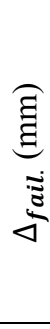 & 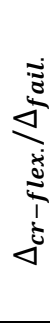 & 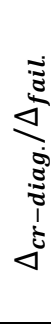 \\
\hline \multirow{3}{*}{ A } & $\begin{array}{l}\hat{\sim} \\
\stackrel{n}{0}\end{array}$ & $\stackrel{\circ}{n}$ & ' & $\stackrel{\circ}{\sim}$ & ' & ర్ర & \multirow{3}{*}{$\frac{N}{\forall}$} & $\stackrel{n}{\text { ñ }}$ & $\stackrel{\widehat{o}}{0}$ & $\stackrel{m}{\dot{\sigma}}$ & 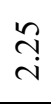 & $\begin{array}{l}\infty \\
\dot{m}\end{array}$ & $\begin{array}{l}\sigma \\
\infty\end{array}$ & 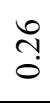 & $\stackrel{\nabla}{\stackrel{+}{0}}$ \\
\hline & 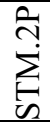 & 8 & $\begin{array}{l}m \\
\stackrel{m}{p}\end{array}$ & $\stackrel{\sim}{\tilde{N}}$ & थֶ? & $\stackrel{?}{\stackrel{P}{+}}$ & & $\stackrel{n}{\circ}$ & $\tilde{\jmath}$ & $\stackrel{\tilde{\sigma}}{\dot{0}}$ & - & $\begin{array}{l}0 \\
i\end{array}$ & $n$ & $\frac{\infty}{0}$ & $\hat{\tilde{n}}$ \\
\hline & $\begin{array}{l}\stackrel{\vec{v}}{\underline{\alpha}} \\
\frac{\alpha}{I}\end{array}$ & $\stackrel{ }{=}$ & $\begin{array}{l}0 \\
\stackrel{0}{0} \\
\stackrel{\gamma}{0}\end{array}$ & ָ̊ & $\begin{array}{l}0 \\
+ \\
+\end{array}$ & ลี & & $\stackrel{0}{=}$ & $\vec{\sim}$ & $\stackrel{\nabla}{\forall}$ & ป઼ & $\stackrel{n}{i}$ & is & $\stackrel{\overbrace{}}{\stackrel{n}{0}}$ & $\underset{\dot{\theta}}{+}$ \\
\hline \multirow{3}{*}{ B } & $\begin{array}{l}\stackrel{\theta}{a} \\
\stackrel{n}{a}\end{array}$ & $\cong$ & 1 & $\stackrel{\sim}{\widetilde{N}}$ & ' & $\stackrel{n}{n}$ & \multirow{3}{*}{$\begin{array}{l}n \\
\stackrel{n}{\infty} \\
\infty\end{array}$} & $\stackrel{\overbrace{}}{\sim}$ & กี & $\begin{array}{l}\hat{b} \\
\dot{0}\end{array}$ & ב & $\tilde{n}$ & $\stackrel{m}{\stackrel{m}{r}}$ & $\stackrel{\sim}{0}$ & $\stackrel{n}{+}$ \\
\hline & 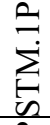 & $n$ & $\overrightarrow{\vec{f}}$ & $\stackrel{n}{\beth}$ & $\underset{ָ}{\widetilde{T}}$ & ஓి & & $\stackrel{\Xi}{\circ}$ & $\stackrel{n}{\tilde{c}}$ & $\stackrel{\infty}{n}$ & $\stackrel{\infty}{-}$ & $m$ & & $\stackrel{+}{m}$ & $\tilde{n}$ \\
\hline & $\begin{array}{l}\alpha \\
\underline{\alpha} \\
\underline{\alpha}\end{array}$ & $\stackrel{8}{8}$ & $\frac{m}{1}$ & $\stackrel{\sim}{\approx}$ & 0 & $\stackrel{\sim}{n}$ & & $\stackrel{m}{=}$ & $\ddot{0}$ & $\begin{array}{l}\hat{\sigma} \\
\dot{0}\end{array}$ & ๙ૂ & $\stackrel{+}{n}$ & $\stackrel{\Re}{\stackrel{7}{+}}$ & $\dot{0}$ & $\underset{0}{\stackrel{+}{0}}$ \\
\hline \multirow{3}{*}{$\mathrm{C}$} & $\stackrel{p}{\rho}$ & $\cong$ & ' & 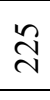 & ' & \begin{tabular}{l}
$\infty$ \\
\multirow{2}{*}{} \\
$\sim$
\end{tabular} & \multirow{3}{*}{$\stackrel{\overbrace{}}{\tilde{r}}$} & $\stackrel{\sim}{\sim}$ & ઼ָ & $\overrightarrow{0}$ & $\stackrel{n}{n}$ & $\begin{array}{l}\text { Uర } \\
\text { i }\end{array}$ & $\hat{n}$ & $\stackrel{N}{0}$ & ஸे \\
\hline & $\sum_{i=1}^{D}$ & $\stackrel{8}{8}$ & $\stackrel{\Upsilon}{\uparrow}$ & $\stackrel{n}{\simeq}$ & $\underset{ָ}{\stackrel{\sim}{N}}$ & $\begin{array}{l}\stackrel{\sim}{\circ} \\
\stackrel{+}{+}\end{array}$ & & ڤ̊ & $\stackrel{\overbrace{}}{0}$ & $\dot{\nabla}_{0}$ & 9 & $\begin{array}{l}\infty \\
\stackrel{N}{\sim}\end{array}$ & nֶ? & ָे & $\stackrel{+}{+}$ \\
\hline & 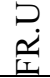 & $\stackrel{n}{n}$ & $\stackrel{\text { }}{+}$ & $\stackrel{\sim}{\approx}$ & 0 & in & & $\stackrel{n}{=}$ & సิ & $\stackrel{f}{+}$ & $\stackrel{0}{\stackrel{2}{2}}$ & ָ̊ & nె & $\hat{\tilde{o}}$ & ñ? \\
\hline
\end{tabular}

The general crack behaviour is presented in detail as follows:

a. The reference specimens DB.2P, DB.1P and DB.U: the first visible flexural cracks appeared in the region of maximum bending moment and extended nearly vertically upward. These cracks were observed at $23-32 \%$ of the ultimate load. Then, first shear cracks appeared at a loading level $41-63 \%$ of the ultimate load.

b. STM.2P, STM.1P and STM.U specimens: the first visible flexural cracks took place in the specimen mid-span at $21-25 \%$ of the ultimate load. These flexural cracks extended vertically upward. After that, the first shear cracks appeared at 41$58 \%$ of the ultimate load.

c. FR.2P, FR.1P and FR.U: the first visible straight cracks appeared at $21-30 \%$ of the ultimate load along the bottom, then the back and front sides of the specimen tie. These flexural cracks were vertical and approximately parallel to each other. While at $44-69 \%$ of the ultimate load, the first shear cracks were developed at the nodal support zones. 
Group A

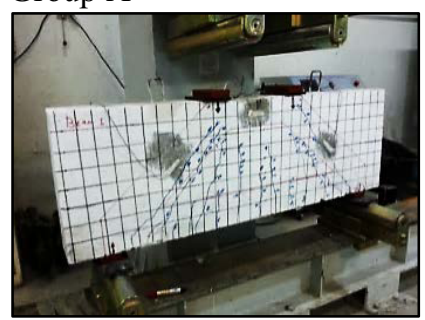

Plate 1. DB.2P

(flexural-shear failure)

\section{Group B}

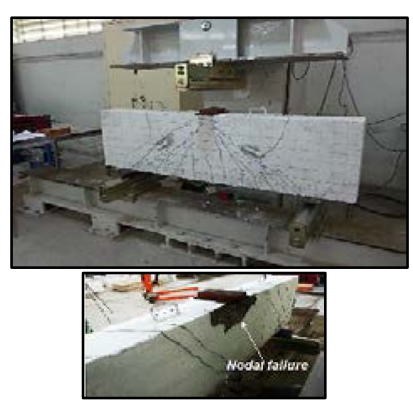

Plate 4. DB.1P

(nodal failure)

\section{Group C}

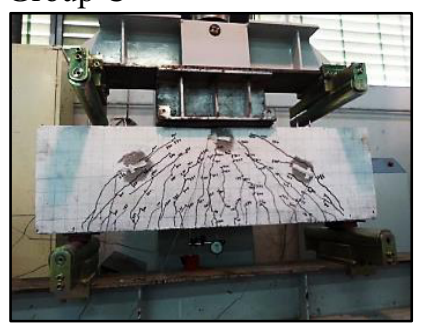

Plate 7. DB.U

(flexural-shear failure)

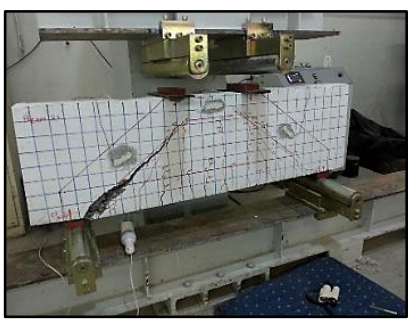

Plate 2. STM.2P

(diagonal splitting failure)

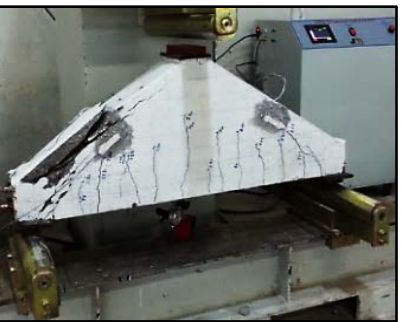

Plate 5. STM.1P

(diagonal compression failure)

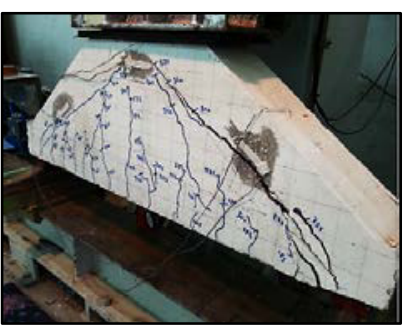

Plate 8. STM.U

(diagonal splitting failure)

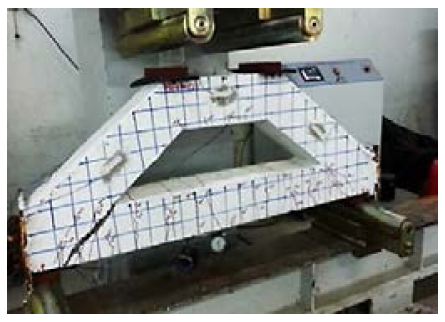

Plate 3. FR.2P

(diagonal splitting failure)

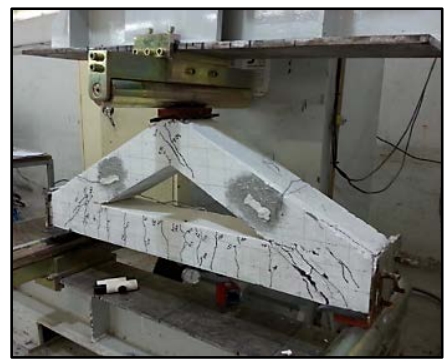

Plate 6. FR.1P

(diagonal splitting failure)

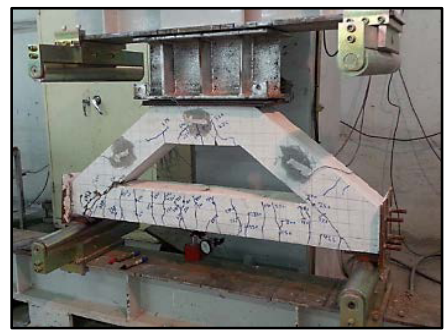

Plate 9. FR.U

(diagonal splitting failure)

Fig. 2. The general crack behaviour.

It has been observed that the width of $P_{c r-f l e x}$ did not exceed the maximum crack width of $0.5 \mathrm{~mm}$ which is specified by [8-10]. While the width of $P_{c r-\text { diag }}$ had exceeded the maximum width of $0.5 \mathrm{~mm}$ specified in [8-10]. Table 4 shows more details about crack characteristics of the experimental SCC specimens at failure loads in which it had also been observed that the widths of the diagonal shear cracks were much wider than those of the flexural cracks. This fact sounded reasonable because the shear failure was dominant.

Table 4 shows that the number of the flexural cracks in the proposed specimens STM.2P, STM.1P, STM.U, FR.2P, FR.1P and FR.U was more than those in the reference specimens DB.2P, DB.1P and DB.U. That took place because there was less concrete around the ties of the proposed specimens in addition to the less main reinforcement that were put in these ties. While the number of the diagonal cracks in STM.2P, STM.1P, STM.U, FR.2P, FR.1P and FR.U specimens was less than those in DB.2P, DB.1P and 
DB.U specimens. That took place because the compressive forces in the reinforced strut splitted the tie at its end (near the node) which prevented the dispersion of shear forces.

Table 4. Crack characteristics of experimental SCC specimens at failure.

\begin{tabular}{|c|c|c|c|c|c|c|}
\hline $\begin{array}{l}\Xi \\
0 \\
0\end{array}$ & $\begin{array}{c}\text { Specimen } \\
\text { designation }\end{array}$ & $\begin{array}{l}P_{\text {exp. }} \\
(\mathrm{kN})\end{array}$ & $\begin{array}{l}1^{\text {st }} \text { flexural } \\
\text { crack width } \\
(\mathrm{mm})\end{array}$ & $\begin{array}{l}1^{\text {st }} \text { shear } \\
\text { crack width } \\
\quad(\mathrm{mm})\end{array}$ & $\begin{array}{l}\text { Number of } \\
\text { flexural cracks } \\
\text { at failure }\end{array}$ & $\begin{array}{c}\text { Number of } \\
\text { shear cracks } \\
\text { at failure }\end{array}$ \\
\hline \multirow{3}{*}{ A } & DB.2P & 562 & 0.3 & 0.83 & 6 & 10 \\
\hline & STM.2P & 470 & 0.22 & 0.7 & 7 & 9 \\
\hline & FR.2P & 522 & 0.26 & 0.75 & 14 & 8 \\
\hline \multirow{3}{*}{ B } & DB.1P & 355 & 0.2 & 0.64 & 5 & 11 \\
\hline & STM.1P & 300 & 0.14 & 0.5 & 12 & 4 \\
\hline & FR.1P & 325 & 0.16 & 0.55 & 10 & 7 \\
\hline \multirow{3}{*}{$\mathrm{C}$} & DB.U & 547.8 & 0.29 & 0.8 & 12 & 16 \\
\hline & STM.U & 420.2 & 0.26 & 0.7 & 10 & 5 \\
\hline & FR.U & 505 & 0.22 & 0.74 & 14 & 5 \\
\hline
\end{tabular}

\subsection{Failure modes}

The conventional reinforced reference deep beams exhibited generally two modes of failure, flexural-shear failure (DB.2P and DB.U) and nodal failure (DB.1P). That is why, during loading, it was seen that the inclined shear cracks developed which preceded by vertical flexural cracks at mid-span. In case of DB.2P and DB.U, the main cracks that caused the final failure propagated upwards from the supports towards the load application points. While in case of DB.1P, high stresses developed under the loaded area which led to a more sudden nodal failure than the flexural-shear failure of DB.2P and DB.U.

While all the proposed specimens in which the paths of struts and ties were reinforced as compression and tension members, respectively failed by diagonal splitting failure (except STM.1P). This was attributed to the horizontal and the vertical components of the reinforced strut compressive force that caused tension and shear, respectively in the tie. These two components led to split the tie at its end. The specimen STM.1P failed by a more sudden destruction of the right strut (which led to diagonal compression failure) than the diagonal splitting failure of the other proposed specimens.

\subsection{Load-deflection behaviour}

The load-deflection curves for the specimens of groups A, B, and C are shown in Figures 3 to 5 , respectively. Generally, in both the conventional deep beams and the proposed specimens, the load-deflection curves were roughly linear in the greater portion of the loading and then the curves started to bend slightly. This general behaviour happened because the shear deformation was the predominant behaviour which led to the brittle failure. This brittle failure decreased the strength of the specimens below the flexural capacity and noticeably decreased the ductility of them. 


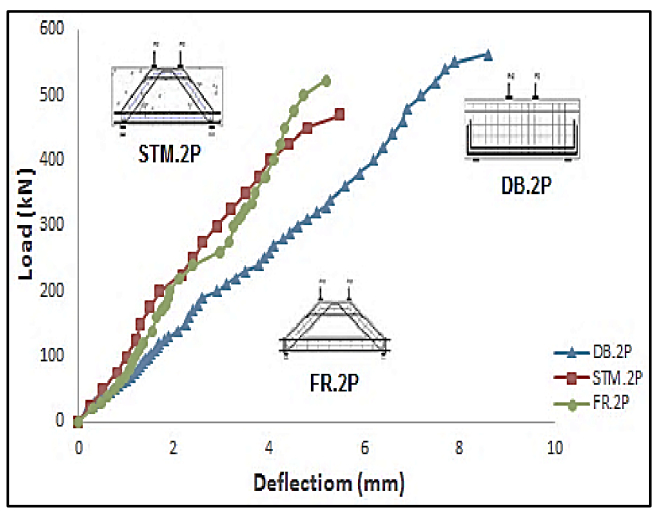

Fig. 3. Load-mid span deflection curves for group A.

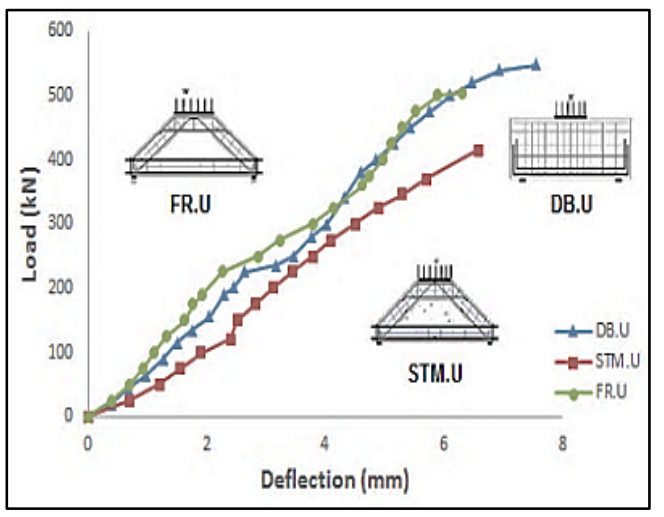

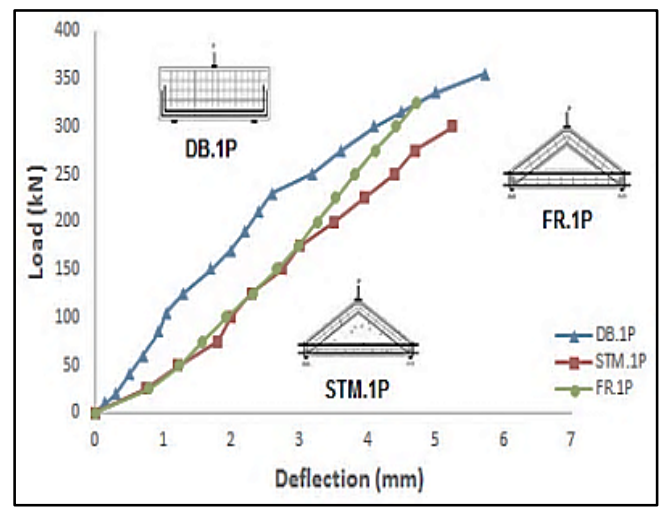

Fig. 4. Load-mid span deflection curves for group B.

Fig. 5. Load-mid span deflection curves for group C.

\subsubsection{Shear strength}

The design of reference specimens were developed by using the Strut and Tie Method of Appendix A, ACI 318M-14. Test results indicated that each reference specimen DB.2P, DB.1P and DB.U resisted loads greater than the theoretical design load of Strut and Tie Method $\left(P_{S T M}\right)$. In more details, experimental results $P_{\text {exp }}$ showed that the Strut and Tie Method is conservative. In this study, in case of central single concentrated force, $P_{\text {exp }}$ was greater than $P_{S T M}$ by $19 \%$. While $P_{\text {exp }}$ was greater than $P_{S T M}$ by about $20 \%$ in the cases of two central concentrated forces and uniformly distributed load.

At the same time, $P_{\text {exp }}$ was greater than $P_{S T M}$ in the cases of the specimens STM.2P, STM.1P, FR.2P, FR.1P and FR.U. The following comparisons between $P_{S T M}$ and $P_{\text {exp }}$ for the proposed specimens are summarized as follows:

1-Group A: $P_{S T M}$ was less than $P_{\text {exp }}$ by $4.8 \%$ and $14.3 \%$ for the cases of STM.2P and FR.2P, respectively.

2-Group B: $P_{\text {STM }}$ was less than $P_{\text {exp }}$ by $4.5 \%$ and $11.8 \%$ for the cases of STM.1P and FR.1P, respectively. 
3-Group C: $P_{\text {STM }}$ was greater than $P_{\text {exp }}$ by $3.6 \%$ for the case of STM.U while it was smaller than $P_{\text {exp }}$ by $13.7 \%$ for the case of FR.U.

It should be noted here that after test the specimen STM.2P, it was noticed that its shoulders had no cracks at all. Therefore, the shoulders of the specimens STM.1P and STM.U were removed later in order to save cost, weight and front side area. Table 5 shows the comparisons between the specimens concerning cost, weight and front side area.

Table 5. Comparison between all specimens.

\begin{tabular}{|c|c|c|c|c|c|c|c|c|c|c|c|}
\hline \multirow{3}{*}{ 官 } & \multirow{3}{*}{ 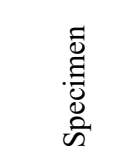 } & \multirow{3}{*}{ 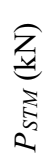 } & \multirow{3}{*}{ 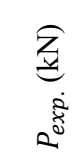 } & \multirow{3}{*}{ 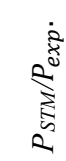 } & \multicolumn{7}{|c|}{$\%$ Decrease in } \\
\hline & & & & & \multicolumn{2}{|c|}{ Weight } & \multirow{2}{*}{$\begin{array}{c}\text { Total } \\
\text { Weight }\end{array}$} & \multicolumn{2}{|c|}{ Cost } & \multirow{2}{*}{$\begin{array}{l}\text { Total } \\
\text { Cost }\end{array}$} & \multirow{2}{*}{$\begin{array}{l}\text { Front } \\
\text { side } \\
\text { area }\end{array}$} \\
\hline & & & & & Conc. & Reinf. & & Conc. & Reinf. & & \\
\hline \multirow{3}{*}{ A } & DB.2P & \multirow{3}{*}{$\frac{\stackrel{+}{*}}{\stackrel{f}{7}}$} & 562 & 0.79 & - & - & - & - & - & - & - \\
\hline & STM.2P & & 470 & 0.95 & -2.4 & 38.6 & 0 & -2 & -9 & -6.17 & 0 \\
\hline & FR.2P & & 522 & 0.85 & 43.2 & 17.3 & 41.5 & 43.1 & -20 & 4.45 & 46.4 \\
\hline \multirow{3}{*}{ B } & DB.1P & \multirow{3}{*}{\begin{tabular}{l}
$n$ \\
$\stackrel{0}{0}$ \\
\multirow{\sim}{*}{}
\end{tabular}} & 355 & 0.8 & - & - & - & - & - & - & - \\
\hline & STM.1P & & 300 & 0.95 & 47.6 & 48.3 & 47.6 & 47 & 20.8 & 30.65 & 51.78 \\
\hline & FR.1P & & 325 & 0.88 & 51 & 45.7 & 50.6 & 49.6 & 13.5 & 27 & 55.35 \\
\hline \multirow{3}{*}{$\mathrm{C}$} & DB.U & \multirow{3}{*}{$\ddot{\gamma}$} & 547.8 & 0.79 & - & - & - & - & - & - & - \\
\hline & STM.U & & 420.2 & 1.03 & 34.3 & 38.6 & 34.2 & 34.4 & -8.5 & 8.3 & 35.7 \\
\hline & FR.U & & 505 & 0.86 & 43.2 & 17.3 & 41.5 & 43.1 & -20 & 4.45 & 46.4 \\
\hline
\end{tabular}

\section{Conclusions}

Removing the concrete where the stress paths of struts and ties do not pass through and then reinforcing these struts and ties did not make significant effects on the behaviour of these proposed specimens in comparison with the conventional reference deep beams. This took place because the stresses from the loading to the supporting points actually pass through these paths that defined by the STM of Appendix A, ACI 318M-14. Based on the experimental test results, the following conclusions can be summarized:

1-Mode of failure:

a. The conventional reinforced reference deep beams failed generally in the well-known flexural-shear failure due to the role of the main, vertical and horizontal reinforcement. That is why, during loading, diagonal cracks appeared at the end of flexural cracks which clarified that combined flexural and shear failure happened in the deep beams.

b. While the proposed specimens in which the paths of struts and ties were reinforced as compression and tension members, respectively failed generally by diagonal splitting failure. This was attributed to the compression force in the reinforced strut that caused tension and shear at the ends of the tie (which led to split the tie at one of these ends).

2-In predicting shear strength of conventional reference deep beams, STM of Appendix A, ACI 318M-14 was conservative and showed lower-bound design when compared with experimental work. STM predicted strengths for the conventional deep beams subjected to 1-concentrated force, 2-concentrated forces and uniformly distributed load were lower than experimental strengths by $19.2 \%, 20.4 \%$ and $20.4 \%$, respectively.

It is wealthy noting that the ultimate capacities of the proposed specimens did not much differ from the theoretical design load of the STM. These negligible differences in ultimate capacities made the proposed specimens good alternatives for the conventional deep beams. 3 -The proposed frames were good alternatives for the conventional deep beams because they saved cost, weight and provided a front side area for service utilities:

a. In case of 2-concentrated forces, the gain in cost, weight and front side area was about $4.45 \%, 41.5 \%$ and $46.4 \%$, respectively. 
b. In case of 1-concentrated force, the gain in cost, weight and front side area was about $27 \%, 50.6 \%$ and $55.35 \%$, respectively.

c. In case of uniformly distributed load, the gain in cost, weight and front side area was about $4.45 \%, 41.5 \%$ and $46.4 \%$, respectively.

4-Generally, in both the conventional deep beams and in the proposed specimens, the loaddeflection curves were approximately linear in the larger part of the load application and then the curves somewhat bent. Therefore, it was obvious that the shear deformation was the predominant behavior which led to brittle failure.

5-There was a general crack behavior for both the reference conventional deep beams and the proposed specimens. In almost specimens, the first visible flexural cracks appeared in the midspan region and extended nearly vertically upward. Then, first shear cracks appeared near the supports. Generally, it had been observed that the first flexural cracks in all specimens were not critical and they did not exceed the maximum width limits. While the first diagonal cracks were more critical and they exceeded the maximum width limits.

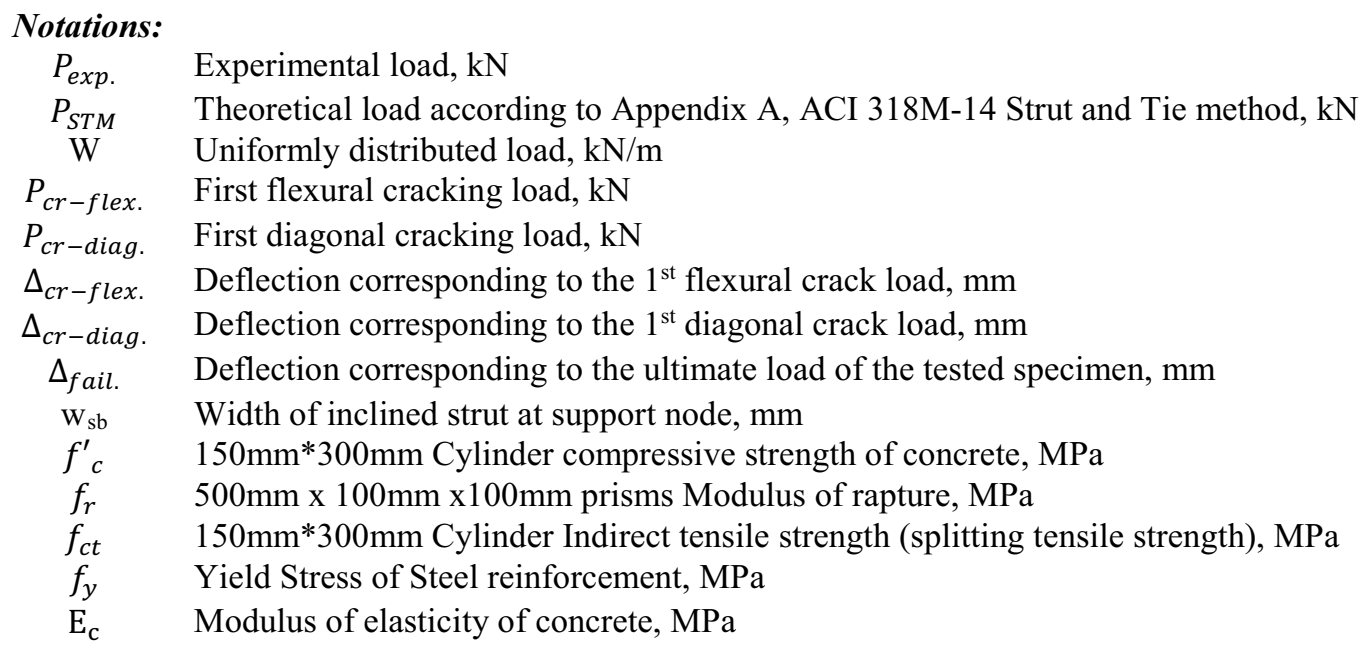

\section{References}

1. Ashour, A. F., \& Yang, K. H. Application of Plasticity Theory to Reinforced Concrete Deep Beams (2008)

2. Schlaich, J., Schäfer, K., \& Jennewein, M. Toward a consistent design of structural concrete. PCI journal, 32(3), 74-150 (1987)

3. Liang, Q. Q., Xie, Y. M., \& Steven, G. P. Topology optimization of strut-and-tie models in reinforced concrete structures using an evolutionary procedure. $A C I$ Structural Journal, 97 (2), 322-330 (2000)

4. Hwang, S. J., Lu, W. Y., \& Lee, H. J. Shear strength prediction for deep beams. Structural Journal, 97(3), 367-376 (2000)

5. ACI Committee, American Concrete Institute, and International Organization for Standardization. Building code requirements for structural concrete (ACI 318-14) and commentary. American Concrete Institute (2014)

6. EFNARC, S. Guidelines for self-compacting concrete. London, UK: Association House, 32-34 (2002)

7. ACI Committee. American Concrete Institute, and International Organization for 
Standardization. Self-consolidating concrete (ACI 237-07). American Concrete Institute (2007)

8. Machida, A. Recommendation for design and construction of concrete structures using continuous fiber reinforcing materials. Tokyo: Research Committee on Continuous Fiber Reinforcing Materials, Japan Society of Civil Engineers (1997)

9. Canadian Standards Association. Design and construction of building components with fibre-reinforced polymers. Toronto: Canadian Standards Association (2012)

10. Canadian Standards Association, CSA Group \& Canadian Standards Association. Canadian highway bridge design code (2014) 